\title{
A Simple Model of Brain CirCulation
}

\author{
NICOLAS SCHMITT \\ ANTOINE SOUBEYRAN
}

CESIFO WORKING PAPER NO. 1484

CATEgOry 7: TRAde Policy

JUNE 2005

Presented at CESifo Area Conference on Global Economy, DeCEMBer 2004

An electronic version of the paper may be downloaded

- from the SSRN website:

www.SSRN.com

- from the CESifo website:

www.CESifo.de 


\title{
A Simple Model of Brain CiRCULATION
}

\begin{abstract}
This paper considers the allocation of two types of individuals differentiated by levels of talent within and between two countries when they choose to be workers or entrepreneurs. The equilibrium with international migrations requires both countries to be sufficiently different in talent endowments and is consistent with individuals moving in one or in both directions whether they are entrepreneurs or workers. Average welfare per capita falls in the country losing highly talented individuals and rises in the country attracting them. However, in both countries, the liberalization of migrations for immigrants, emigrants or both is always supported by majority voting.
\end{abstract}

JEL Code: F2, F22, J61.

\author{
Nicolas Schmitt \\ Department of Political Economics \\ University of Geneva \\ 1211 Geneva 4 \\ Switzerland \\ schmitt@ecopo.unige.ch
}

\author{
Antoine Soubeyran \\ GREQAM \\ Château La Farge \\ 13290 Les Milles \\ France \\ soubey@romarin.univ-aix.fr
}

We would like to thank participants to the 2nd CESIfo conference on Global Economy held in Munich on December 10-11, 2004 for useful comments. 


\section{Introduction}

The paper investigates a two-country model of one- and two-way international migrations of individuals differentiated by levels of talent and working in a single industry. During the last 20 years, migrations of skilled labor have increased significantly (OECD, 2001) and they are now influencing the size and the structure of several industries. This phenomenon has become sufficiently widespread and multi-faceted that it is now often described as 'brain circulation' (Johnson and Regets, 1998). In North America for instance, an average of about 29,000 individuals migrated yearly from the US to Canada between 1997 and 2002 while about 73,000 individuals moved in the other direction. ${ }^{1}$ Although these flows are small with respect to population, evidence suggests that these migrants are highly skilled in terms of education or income (Gera et al., 2004). They are mostly concentrated in professions like managers, executives, engineers, scientists and entrepreneurs, and work predominently in knowledge-based industries like services and information technology. ${ }^{2}$ Zucker and Darby $(1995,1999)$ have documented the flows of star scientists across borders and how these highly talented individuals have shaped the biotechnology industry in its early stages. ${ }^{3}$ Efforts to attract foreign software specialists in Germany, return migrations to India and to China are other examples of the growing importance of talent for many industries. Clearly, economists should investigate brain circulation.

To address this issue, we consider a model with two key components. First, individuals working in a given industry are differentiated according to talent (skill or ability), which for our purpose is treated as exogenous. Second, all individuals choose to be workers or entrepreneurs. This determines wage and the number of firms (i.e., entrepreneurs). Because

\footnotetext{
${ }^{1}$ See Gera et al. (2004) and Harris (2004). A large proportion of these flows are temporary migrating professionals benefiting from NAFTA-TN visas.

${ }^{2}$ OECD (2002) reports that 'a quarter of Silicon Valley firms in 1998 were headed by immigrants from China and India and collectively created 52'300 jobs and generated almost USD17 billion in sales'.

${ }^{3}$ For example, during the 1990s, they identified 417 star bioscientists worldwide; the US attracted 26 of them and lost 20 while Canada, Switzerland and the UK had a net total loss of 19, despite attracting 9 (Zucker and Darby, 1999).
} 
individuals differ in talent levels, the model exhibits increasing returns to entrepreneur's ability. Accordingly, firms may be differentiated in terms of size and profitability. Migrations modify directly the industry structure and indirectly by influencing who is entrepreneur. The model then allows us to analyze whether a country wishes to liberalize migrations of talented individuals.

Restricting the analysis to two types of talent, the paper makes four points. First, migrations require the countries not only to be different but to be sufficiently so. Second, the equilibrium can exhibit two-way or one-way international migrations by talent types and because migrations involve both workers and entrepreneurs, migrations can also be expressed with respect to activities. Third, migrations impact the number, the size and the distribution of firms. Finally, although countries with different talent endowments have generally conflicting incentives about migrations based on average welfare per capita, they always choose to allow migrations when such a decision is taken by majority voting. This is true whether migration policy is about immigrants, emigrants or both.

The literature on international mobility of skilled individuals has traditionally investigated the impact of the loss of human capital and of the loss of returns to public investments in training. We ignore these issue reviewed by Bhagwati and Wilson (1989). Treating talent as exogenous, we also ignore how migrations can affect human capital formation (Stark, 2003). This paper is related to Rauch (1991) who uses Lucas (1978)'s model of agent's choice of activity. However Rauch sets the choice of activity in a Heckscher-Ohlin-Samuelson model to investigate the links between patterns of trade and migrations. To concentrate on the patterns of migrations and on industry structure, our model has only one sector. Several articles have considered the role of talent and entrepreneurs in international trade. Among them, Manasse and Turrini (2001) look at trade in products differentiated by quality where quality depends on entrepreneur's skill. Grossman (1984) investigates how opening a country to trade or to FDI affects the choice of becoming entrepreneurs when entrepreneurship involves risk. These papers however do not consider international migrations.

The paper is organized as follows. In the next Section, the basic structure of the model 
is laid out and the equilibrium without migrations is derived. The different pattern of migrations are analyzed in Section 3. In Section 4, we consider welfare and whether these countries allow migrations to occur. Section 5 concludes.

\section{The Model and Equilibrium without Migration}

The model is based on Lucas (1978) and Murphy et al. (1991). Consider two countries, A and $\mathrm{B}$, trading freely one homogeneous good but with no international migration. There are two types of talent in the population of each country, $\left[\theta_{1}, \theta_{2}\right]$ with $\theta_{1}<\theta_{2}$. The number of individuals with talent $\theta_{1}\left(\theta_{2}\right)$ in country $i$ is $\varphi_{1}^{i} \geq 0$ (respectively, $\varphi_{2}^{i} \geq 0$ ). The population is fully employed and each individual can always choose to be either a worker or an entrepreneur. A firm is defined as an entrepreneur with talent $\theta_{j}(j=1,2)$ and employs workers at wage $w^{i}$. Talent measures how an entrepreneur exploits the country-specific technology $\chi^{i}$ and a worker supplies one unit of labor. ${ }^{4}$ The entrepreneur's earning is equal to firm profit and thus to,

$$
\pi^{i}\left(\theta_{j}\right)=p \chi^{i} \theta_{j} f(l)-w^{i} l,
$$

where $p$ is the output price and $f(l)$, the production function for $l$ workers employed by the firm. We assume $f($.$) is the same in both countries and exhibits decreasing marginal labor$ productivity. The labor and the output markets are competitive in both countries. With free trade, the output price is given and identical in both countries. Without loss of generality, we set $p=1$ and assume that $f(l)=l^{\frac{1}{2}}$.

Maximizing (1) with respect to $l$, the number of workers hired by $\theta_{j}$-entrepreneur is

$$
l^{i}\left(\theta_{j}\right)=\left(\frac{\chi^{i} \theta_{j}}{2 w^{i}}\right)^{2}
$$

and the corresponding profit is

$$
\pi^{i}\left(\theta_{j}\right)=\frac{\left(\chi^{i} \theta_{j}\right)^{2}}{4 w^{i}}
$$

\footnotetext{
${ }^{4}$ The fact that talent matters only for entrepreneur is without consequence; what is important is that the returns to entrepreneurs' talent increases relative to alternative occupations.
} 
Hence, firm size, measured by employment, and profit decrease with higher wages and increase with talent because revenue increases with talent but not cost. Increasing returns to talent induce individuals to become entrepreneurs on two counts: they earn higher profit for a given firm size and they spread their talent over a larger firm scale.

The individual's decision to be a worker or an entrepreneur is based on the higher return of the two activities. Since profit increases with $\theta_{j}$, there are three possible talent allocations: some (but not all) $\theta_{1}$-individuals are entrepreneurs; all $\theta_{1}$-individuals are workers and all $\theta_{2^{-}}$ individuals are entrepreneurs (specialization by talent); and some (but not all) $\theta_{2}$-individuals are entrepreneurs.

Each of these cases is valid under different parameter values. Since $\theta_{1}$-individuals can be entrepreneurs and workers in the first case, they must be indifferent between the two activities and profit must equal wage. From $(3), \widehat{\pi}^{i}\left(\theta_{1}\right)=\widehat{w}^{i}=\frac{\chi^{i} \theta_{1}}{2}$ and it follows that $\widehat{\pi}^{i}\left(\theta_{2}\right)=\frac{\chi^{i} \theta_{2}}{2} \frac{\theta_{2}}{\theta_{1}}$. Thus there are two groups of firms in terms of size and profitability. The larger and more profitable firms are headed by $\theta_{2}$-entrepreneurs and the smaller and less profitable firms are headed by $\theta_{1}$-entrepreneurs. The proportion of $\theta_{1}$-individuals who are entrepreneurs in country $i\left(\lambda_{1}^{i}\right)$ is determined by the equilibrium in the labor market. Since workers are only found among $\theta_{1}$-individual, the supply of workers is $L_{S}^{i}=\left(1-\lambda_{1}^{i}\right) \varphi_{1}^{i}$. Using (2) and given the two groups of firms, the demand for workers is $L_{D}^{i}=\lambda_{1}^{i} \varphi_{1}^{i}\left[\frac{\chi^{i} \theta_{1}}{2 w^{i}}\right]^{2}+\varphi_{2}^{i}\left[\frac{\chi^{i} \theta_{2}}{2 w^{i}}\right]^{2}$ so that $\lambda_{1}^{i}=\frac{1}{2}\left[1-\frac{\varphi_{2}^{i}}{\varphi_{1}^{i}}\left(\frac{\theta_{2}}{\theta_{1}}\right)^{2}\right]$. Since $0<\lambda_{1}^{i}<1$, this case arises when $0<\frac{\varphi_{2}^{i}}{\varphi_{1}^{i}}<\left(\frac{\theta_{1}}{\theta_{2}}\right)^{2}<1$, implying there are relatively few $\theta_{2}$-individuals. We call it the 'few-talent case'.

In the second case where there is specialization by talent, all $\theta_{1}$-individuals are workers and all $\theta_{2}$-individuals are entrepreneurs. Hence, the labor supply is equal to $\varphi_{1}^{i}$ and the labor demand is $L_{D}^{i}=\varphi_{2}^{i}\left[\frac{\chi^{i} \theta_{2}}{2 w^{i}}\right]^{2}$, resulting in an equilibrium wage $\widehat{w}^{i}=\frac{\chi^{i} \theta_{2}}{2}\left(\frac{\varphi_{2}^{i}}{\varphi_{1}^{i}}\right)^{1 / 2}$. Given (3), profit becomes $\widehat{\pi}^{i}\left(\theta_{2}\right)=\frac{\chi^{i} \theta_{2}}{2}\left(\frac{\varphi_{1}^{i}}{\varphi_{2}^{i}}\right)^{1 / 2}$. Thus, all the firms have the same size and profitability but wage and profit now directly depend on the $\theta_{1}$ - and $\theta_{2}$-population. This is an equilibrium provided that no individual wants to switch activity and thus this case requires $\left(\frac{\theta_{1}}{\theta_{2}}\right)^{2}<\frac{\varphi_{2}^{i}}{\varphi_{1}^{i}}<1$. There are now relatively more $\theta_{2}$-individuals than in the first case and we call it the 'intermediate case'. 
In the third case, $\theta_{2}$-individuals can be entrepreneurs or workers and must be indifferent between the two activities $\left(\widehat{w}^{i}=\widehat{\pi}^{i}\left(\theta_{2}\right)\right)$. All workers (be they $\theta_{1}$ or $\theta_{2}$ ) have the same wage $\widehat{w}^{i}=\frac{\chi^{i} \theta_{2}}{2}$ and all the firms are identical in size and profitability. The proportion of entrepreneurs in the $\theta_{2}$-population $\left(\lambda_{2}^{i}\right)$ is determined by the labor market equilibrium and is equal to $\lambda_{2}^{i}=\frac{1}{2}\left[\frac{\varphi_{1}^{i}}{\varphi_{2}^{i}}+1\right]$. This case requires a relatively large number of $\theta_{2}$-individuals $\left(\frac{\varphi_{2}^{i}}{\varphi_{1}^{i}}>1\right)$ and we call it the 'many-talent case'.

Defining earnings by type of individuals (i.e., $G_{0}^{i}\left(\theta_{1}\right), G_{0}^{i}\left(\theta_{2}\right)$ ), relative earnings for each of the three cases, few-talent, intermediate and many-talent case, are respectively,

$$
\begin{array}{ll}
G_{0}^{i}\left(\theta_{1}\right)=\frac{\chi^{i} \theta_{1}}{2}<G_{0}^{i}\left(\theta_{2}\right)=\frac{\chi^{i} \theta_{2}}{2} \frac{\theta_{2}}{\theta_{1}} & \text { if } 0 \leq \frac{\varphi_{2}^{i}}{\varphi_{1}^{i}}<\left(\frac{\theta_{1}}{\theta_{2}}\right)^{2} ; \\
G_{0}^{i}\left(\theta_{1}\right)=\frac{\chi^{i} \theta_{2}}{2}\left(\frac{\varphi_{2}^{i}}{\varphi_{1}^{i}}\right)^{1 / 2}<G_{0}^{i}\left(\theta_{2}\right)=\frac{\chi^{i} \theta_{2}}{2}\left(\frac{\varphi_{1}^{i}}{\varphi_{2}^{i}}\right)^{1 / 2} & \text { if }\left(\frac{\theta_{1}}{\theta_{2}}\right)^{2}<\frac{\varphi_{2}^{i}}{\varphi_{1}^{i}}<1 ; \\
G_{0}^{i}\left(\theta_{1}\right)=G_{0}^{i}\left(\theta_{2}\right)=\frac{\chi^{i} \theta_{2}}{2} & \text { if } \frac{\varphi_{2}^{i}}{\varphi_{1}^{i}}>1 .
\end{array}
$$

Except for the intermediate case, the equilibrium earnings are independent of the relative number of $\varphi_{j}$-individuals. Keeping in mind that, although $\theta_{1}$-individual's earnings could be firm's profit (as in the few-talent case), it always represents wage since there are always workers among $\theta_{1}$-individuals. Similarly, although $\theta_{2}$-individual's earnings could be wage, it always represents profit. Fig.1a and $1 \mathrm{~b}$ illustrate (4) and the easiest way to interpret them is thus to consider $G_{0}^{i}\left(\theta_{1}\right)$ as wage and $G_{0}^{i}\left(\theta_{2}\right)$ as profit.

In the first case, since $\theta_{1}$-individuals are relatively numerous, the wage is low relative to profit. When there are relatively more $\theta_{2}$-individuals (the intermediate case), the smaller and less profitable firms disappear and all entrepreneurs are $\theta_{2}$-type. As the relative size of the $\theta_{2}$-population rises, the number of firms increases, the demand for labor rises and so does the equilibrium wage. With costs rising, firm profitability and size shrink. In the many-talent case, wage and profit are identical, and the demand for labor is sufficiently high for some $\theta_{2}$-individuals to be workers. As a result, wage is the highest and profit is the lowest of the three cases.

Fig.1c shows employment per firm and Fig.1d, the proportion of entrepreneurs (or firms) in the total population $h_{i}$. In the few-talent case, the number of firms falls when $\varphi_{2}^{i} / \varphi_{1}^{i}$ 

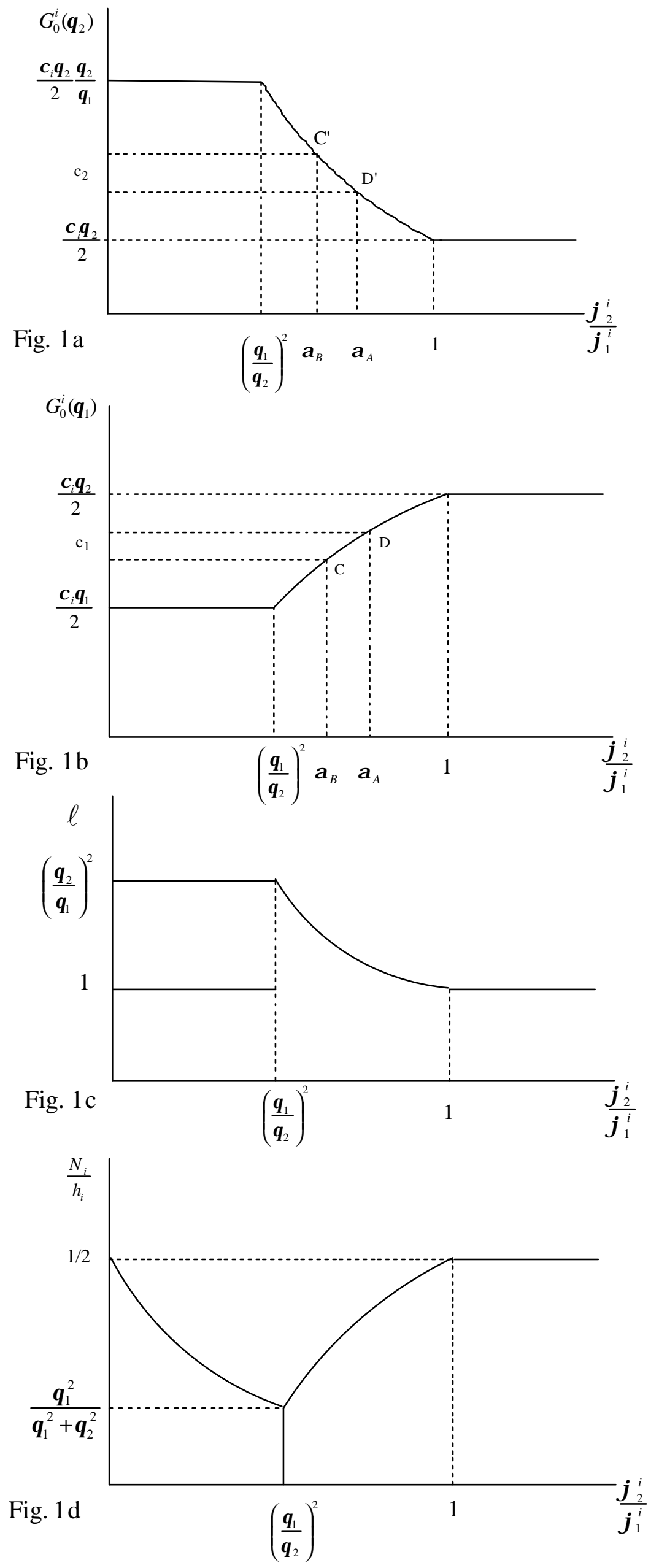
increases. This is because, although the number of firms with $\theta_{2}$-entrepeneurs rises, the number of firms with $\theta_{1}$-entrepreneurs falls even more. Supply and demand of labor remain constant however and wage is constant. This means that, on average, firms are becoming bigger with $\varphi_{2}^{i} / \varphi_{1}^{i}$ rising. As soon as all the less efficient firms have disappeared, the wage starts increasing as the number of firms with $\theta_{2}$-entrepreneurs keeps rising. As a result, employment per firm falls. When $\varphi_{2}^{i} / \varphi_{1}^{i}>1$, the proportion of entrepreneurs in the population remains constant and so are wages and profits. ${ }^{5}$ Since the average employment per firm is now the lowest of the three cases, there is a relatively large number of small firms.

Even though quite simple, the model generates three distinct cases where profit, wage, firm size and the number of firms are different. We now set the model in a two-country environment with international mobility to investigate the patterns of migrations and their effects on activity choices.

\section{$3 \quad$ Equilibria with Migrations}

To concentrate on migration patterns, we assume that the two countries use the same technology $\left(\chi^{A}=\chi^{B}=1\right)$. Then, in our model, a difference in talent endowments is not sufficient to generate migrations. For example, the two countries could be different while both belonging to the few-talent case without migrations happening. This is so because earnings are the same for both types of individuals across the two countries. To generate migrations, the two countries should be sufficiently different (i.e., belong to different cases or be both in the intermediate case). From now on, we assume that country A is a many-talent case $\left(\alpha_{0}^{A}=\varphi_{2}^{A} / \varphi_{1}^{A}>1\right)$ and B is a few-talent case $\left(\alpha_{0}^{B}=\varphi_{2}^{B} / \varphi_{1}^{B}<\left(\theta_{1} / \theta_{2}\right)^{2}<1\right)$. Then, Fig.1a and $1 \mathrm{~b}$ show that $\theta_{1}$-individuals, relatively abundant in $\mathrm{B}$, may have an incentive to migrate to A because of earnings differential. Conversely, $\theta_{2}$-individuals, relatively abundant in A,

\footnotetext{
${ }^{5}$ In the few talent case, the number of firms $N^{i}$ is $\lambda_{1}^{i} \varphi_{1}^{i}+\varphi_{2}^{i}$. Given $\lambda_{1}^{i}$ and $h^{i}=\varphi_{1}^{i}+\varphi_{2}^{i}$, $\partial\left(N^{i} / h^{i}\right) / \partial\left(\varphi_{2}^{i} / \varphi_{1}^{i}\right)<0$ and $\partial^{2}\left(N^{i} / h^{i}\right) / \partial\left(\varphi_{2}^{i} / \varphi_{1}^{i}\right)^{2}>0$. In the intermediate case, the number of firms is $N^{i}=\varphi_{2}^{i}$ so that $\partial\left(N^{i} / h^{i}\right) / \partial\left(\varphi_{2}^{i} / \varphi_{1}^{i}\right)>0$ and $\partial^{2}\left(N^{i} / h^{i}\right) / \partial\left(\varphi_{2}^{i} / \varphi_{1}^{i}\right)^{2}<0$. In the many talent case, $N^{i}=\lambda_{2}^{i} \varphi_{2}^{i}$. Given $\lambda_{2}^{i}, N^{i} / h^{i}=1 / 2$.
} 
may have an incentive to migrate to $\mathrm{B}$. While this pattern of migrations is standard, the fact that two-way migrations can be evaluated not only for types of individuals but also for activities is interesting. This is so because, as shown in Section 2, in few-talent country B, $\theta_{1}$-individuals are both workers and entrepreneurs and have an incentive to migrate. Similarly for country $\mathrm{A}$ with respect to $\theta_{2}$-individuals. Hence, the model can generate two-way migrations among workers and entrepreneurs and two questions require further analysis. First, what are the circumstances under which one-way or two-way migrations between A and B occur? Second, how do the two countries compare in the migration equilibrium and what are the possible outcomes?

Assume that $c_{1}$ (respectively, $c_{2}$ ) is the migration cost of a $\theta_{1^{-}}\left(\theta_{2^{-}}\right)$individual. Clearly, migrations will occur only when, in the equilibrium without migrations, earnings net of migration costs is higher in the destination country than earnings in the country of origin. Given the migration pattern described above, we denote by $x \geq 0$ the number of $\theta_{1}$-individuals (workers and entrepreneurs) who migrate from $\mathrm{B}$ to $\mathrm{A}$ and by $y \geq 0$, the number of $\theta_{2^{-}}$ individuals who migrate from A to B. These individuals have an incentive to move $(x>0$, $y>0)$ when the no-migration equilibrium net earnings $\left(N G_{0}\right)$ are

$$
\begin{aligned}
& N G_{0}\left(\theta_{1}\right)=\left[G_{0}^{A}\left(\theta_{1}\right)-c_{1}\right]-G_{0}^{B}\left(\theta_{1}\right)>0 \\
& N G_{0}\left(\theta_{2}\right)=\left[G_{0}^{B}\left(\theta_{2}\right)-c_{2}\right]-G_{0}^{A}\left(\theta_{2}\right)>0 .
\end{aligned}
$$

Suppose both conditions hold, the equilibrium with two-way migrations determining $x$ and $y$ requires that

$$
\begin{aligned}
& N G\left(\theta_{1}\right)=\left[G^{A}\left(\theta_{1}\right)-c_{1}\right]-G^{B}\left(\theta_{1}\right)=0 ; \\
& N G\left(\theta_{2}\right)=\left[G^{B}\left(\theta_{2}\right)-c_{2}\right]-G^{A}\left(\theta_{2}\right)=0
\end{aligned}
$$

since individuals must be indifferent between net earnings in the destination country and earnings in the country of origin.

Another possible outcome is one-way migration. If it is from $\mathrm{B}$ to $\mathrm{A}(x>0 ; y=0)$, (5) and (7) still hold but (6) and (8) must be negative or equal to zero and conversely for one-way migration from A to $\mathrm{B}(x=0 ; y>0$ when (6) and (8) hold and (5) and (7) 
$\leq 0)$. The conditions (5) and (6) indicate immediately that two-way migrations necessitate relatively low migration costs with respect to the talent (or productivity) differential (i.e., $c_{1}<\left[\theta_{2}-\theta_{1}\right] / 2$ and $\left.c_{2}<\left[\theta_{2} / \theta_{1}\right]\left[\theta_{2}-\theta_{1}\right] / 2\right)$ and thus that one-way migration requires one of the migration costs to be relatively high. If these conditions are necessary, they are not sufficient (we have ignored (7) and (8)). We now characterize the migration equilibria more precisely, especially the two-way migration equilibrium.

Migrations change country A's relative talent endowment such that $\alpha^{A}=\frac{\varphi_{s}^{A}-y}{\varphi_{1}^{A}+x}<\alpha_{0}^{A}$ and country B's such that $\alpha^{B}=\frac{\varphi_{s}^{B}+y}{\varphi_{1}^{B}-x}>\alpha_{0}^{B}$. Suppose first migrations make A and B more alike by bringing both countries in the intermediate-case space $\left(\alpha_{0}^{B}<\left(\theta_{1} / \theta_{2}\right)^{2}<\alpha^{B}<1\right.$ and $\left.\left(\theta_{1} / \theta_{2}\right)^{2}<\alpha^{A}<1<\alpha_{0}^{A}\right)$. In this case, earnings in the migration equilibrium are $G^{A}\left(\theta_{1}\right)=\frac{\theta_{2}}{2} \sqrt{\alpha^{A}}, G^{A}\left(\theta_{2}\right)=\frac{\theta_{2}}{2}\left(1 / \sqrt{\alpha^{A}}\right) ; G^{B}\left(\theta_{1}\right)=\frac{\theta_{2}}{2} \sqrt{\alpha^{B}}$ and $G^{B}\left(\theta_{2}\right)=\frac{\theta_{2}}{2}\left(1 / \sqrt{\alpha^{B}}\right.$ ) (see $(4))$.

Proposition 1 Two-way migrations ( $x>0, y>0$ ), such that countries $A$ and $B$ fall in the intermediate range, require $c_{1} \theta_{2} /\left(\theta_{2}-2 c_{1}\right)<c_{2}<c_{1} \theta_{2}^{2} /\left(\theta_{1}^{2}+2 c_{1} \theta_{1}\right)$. In this equilibrium, the migration cost for $\theta_{1}$-individuals is lower than for $\theta_{2}$-individuals and the two countries are never identical $\left(\alpha^{B}<\alpha^{A}\right)$.

Proof. Observe from (4) that $G^{i}\left(\theta_{1}\right) G^{i}\left(\theta_{2}\right)=\left[\theta_{2} / 2\right]^{2}(i=A, B)$, so that (8) can be rewritten as $c_{1} \theta_{2}^{2} / 4 c_{2}=G^{A}\left(\theta_{1}\right) G^{B}\left(\theta_{1}\right)$. In the intermediate case with migrations, this last equality and (7) become respectively $\sqrt{\alpha^{A}} \sqrt{\alpha^{B}}=n_{1} / n_{2}$ and $\sqrt{\alpha^{A}}-\sqrt{\alpha^{B}}=n_{1}$ where $n_{1}=2 c_{1} / \theta_{2}$ and $n_{2}=2 c_{2} / \theta_{2}$. Solving these two equations,

$$
\begin{aligned}
\sqrt{\alpha^{A}} & =\left(1 / 2 n_{2}\right)\left[n_{1} n_{2}+\sqrt{\left(n_{1} n_{2}\right)^{2}+4 n_{1} n_{2}}\right] \\
\sqrt{\alpha^{B}} & =\left(1 / 2 n_{2}\right)\left[-n_{1} n_{2}+\sqrt{\left(n_{1} n_{2}\right)^{2}+4 n_{1} n_{2}}\right] .
\end{aligned}
$$

Hence, $\alpha^{B}<\alpha^{A}$. Since $0<\alpha^{A}<1,0<\sqrt{\alpha^{A}} \sqrt{\alpha^{B}}=n_{1} / n_{2}<1$ and $c_{2}>c_{1}>0$. Moreover, in the intermediate case, $\left(\theta_{1} / \theta_{2}\right)^{2}<\alpha_{B}<\alpha_{A}<1$ which gives rise to two conditions: $\theta_{1} / \theta_{2}<\sqrt{\alpha_{B}}$ and $\sqrt{\alpha_{A}}<1$. With (9) and (10), the first inequality leads to $n_{2}>n_{1} /\left(1-n_{1}\right)$ and the second to $\left(\theta_{1} / \theta_{2}\right)^{2}+n_{1}\left(\theta_{1} / \theta_{2}\right)<n_{1} / n_{2}$. Together they define the sufficient range of $c_{2}$ over which two-way migrations hold when $\mathrm{A}$ and $\mathrm{B}$ fall in the intermediate case. 
In addition to be low relative to the talent differential, the two migration costs must be relatively similar but they cannot be identical. Since at least one migration cost is positive, the two countries cannot become identical with two-way migrations. To understand why $c_{1}$ and $c_{2}$ are different, consider Fig.1a,b. In equilibrium, the difference between $C^{\prime}$ and $D^{\prime}$ (equal to $c_{2}$ ) is greater than the difference between $C$ and $D$ (equal to $c_{1}$ ). This comes from the property that, in the intermediate case, $G\left(\theta_{2}\right)$ is more sensitive than $G\left(\theta_{1}\right)$ to a change in $\varphi_{2}^{i} / \varphi_{1}^{i}{ }^{6}$. This arises because a difference in wage between $\mathrm{A}$ and $\mathrm{B}$ must translate into a more than proportional difference in profits since a higher wage lowers profit directly and indirectly through a smaller firm size.

The migration flows can now be characterized. Since $\alpha^{A}=\frac{\varphi_{s}^{A}-y}{\varphi_{1}^{A}+x}$ and $\alpha^{B}=\frac{\varphi_{s}^{B}+y}{\varphi_{1}^{B}-x}$, (9) and (10) define two equations with $x$ and $y$ as the two unknowns. Defining $\mu^{A}=$ $\left[\left(1 / 2 n_{2}\right)\left(n_{1} n_{2}+\sqrt{\left(n_{1} n_{2}\right)^{2}+4 n_{1} n_{2}}\right)\right]^{2}$ and $\mu^{B}=\left[\left(1 / 2 n_{2}\right)\left(-n_{1} n_{2}+\sqrt{\left(n_{1} n_{2}\right)^{2}+4 n_{1} n_{2}}\right)\right]^{2}$, the migrations flows of $\theta_{1}$ - and $\theta_{2}$-individuals when the two economies are in the intermediate range are respectively

$$
x=\frac{\varphi_{2}^{A}+\varphi_{2}^{B}-\left(\mu^{A} \varphi_{1}^{A}+\mu^{B} \varphi_{1}^{B}\right)}{\mu^{A}-\mu^{B}} \text { and } y=\frac{\mu^{A} \mu^{B}\left(\varphi_{1}^{A}+\varphi_{1}^{B}\right)-\left(\mu^{A} \varphi_{2}^{B}+\mu^{B} \varphi_{2}^{A}\right)}{\mu^{A}-\mu^{B}} .
$$

Since workers and entrepreneurs have the same incentive to migrate among $\theta_{1}$-individuals in $\mathrm{B}$ and among $\theta_{2}$-individuals in $\mathrm{A}, x$ and $y$ include both workers and entrepreneurs. Hence, this equilibrium is consistent with two-way migrations of both entrepreneurs and workers. Observe however that some migrants switch activity. Since all $\theta_{1}$-individuals are workers and all $\theta_{2}$-individuals are entrepreneurs in the equilibrium with migrations, some $\theta_{1}$-individuals who were entrepreneurs in country B before migrating are now workers in country A and some $\theta_{2}$-individuals who where workers before migrating are now entrepreneurs in country B. Overall, allowing migrations increases the number of entrepreneurs (or firms) in the two countries provided that $\varphi_{2}^{A}+\varphi_{2}^{B}\left(\theta_{2} / \theta_{1}\right)^{2}-\left(\varphi_{1}^{A}+\varphi_{1}^{B}\right)>0$ and thus provided that the overall population of $\theta_{1}$-individuals is not too large as compared to $\theta_{2}$-individuals. ${ }^{7}$

\footnotetext{
${ }^{6}$ Specifically, $\left|\partial G\left(\theta_{1}\right) / \partial\left(\varphi_{2} / \varphi_{1}\right)\right|<\left|\partial G\left(\theta_{2}\right) / \partial\left(\varphi_{2} / \varphi_{1}\right)\right|$ when $\varphi_{2} / \varphi_{1}<1$.

${ }^{7}$ The change in the total number of firms from allowing migrations is equal to the difference between the number of entrepreneurs with migrations $\left(\varphi_{2}^{A}+\varphi_{2}^{B}\right)$ and without migrations $\left(\lambda_{2} \varphi_{2}^{A}+\lambda_{1} \varphi_{1}^{B}+\varphi_{2}^{B}\right)$.
} 
As soon as the parameters of the model are outside the range given in Proposition 1, there cannot be two-way migrations. This implies that one-way migrations involve neither too low, nor too similar migration costs. The following proposition summarizes the results.

Proposition 2 One-way migration of $\theta_{1}$-individuals $(x>0 ; y=0)$ is consistent with the equilibrium in which the two countries fall in the intermediate case provided that $c_{1}<$ $\left[\theta_{2}-\theta_{1}\right] / 2$ and $c_{2} \geq\left[\theta_{2} / \theta_{1}\right]\left[\theta_{2}-\theta_{1}\right] / 2$. One-way migration of $\theta_{2}$-individuals $(x=0 ; y>0)$ is consistent with the equilibrium in which the two countries fall in the intermediate case provided that $c_{1} \geq\left[\theta_{2}-\theta_{1}\right] / 2$ and $c_{2}<\left[\theta_{2} / \theta_{1}\right]\left[\theta_{2}-\theta_{1}\right] / 2$. The first case requires $c_{2}>c_{1}$ and the second case is consistent with $c_{1}=c_{2}>0$.

Proof. See the Appendix.

Since $c_{2}>c_{1}$ is needed for two-way migrations, it must be a fortiori the case when only $\theta_{1}$-individuals migrate. Similarly, there must be a relatively high migration $\operatorname{cost} c_{1}$ to discourage $\theta_{1}$-individuals from migrating when $x=0$. This explains why $c_{1}=c_{2}$ is consistent with this equilibrium. However since migration costs are positive when equal, the two countries cannot become identical even in this case.

Other equilibria with migrations are possible. With higher migration costs for instance, we could still have migration equilibria in which the two countries are less different than in the intial equilibrium but more different than when both countries fall in the intermediate case. Proposition 3 summarizes the possibilities.

Proposition 3 Given the equilibrium without migration in which country A has many talents and country $B$ as few talents, allowing migrations of $\theta_{1}$ - and $\theta_{2}$-individuals leads to two additional equilibria: (i) A has still many talents and $B$ falls in the intermediate case, and (ii) A falls in the intermediate case and B has still few talents. These cases involve one-way migrations of $\theta_{1}$ - or $\theta_{2}$-individuals.

Proof. See the Appendix. 
All other combinations are inconsistent with an equilibrium with migrations ${ }^{8}$. Even if a country stays the same type with migrations, changes do occur. For instance, from Section 2, A has a proportion of $\lambda_{2}^{A}=\frac{1}{2}\left[\frac{1}{\varphi_{2}^{A} / \varphi_{1}^{A}}+1\right]$ entrepreneurs among $\theta_{2}$-individuals so that $\frac{\partial \lambda_{2}}{\partial\left(\varphi_{2} / \varphi_{1}\right)}<0$. Since $\varphi_{2}^{A} / \varphi_{1}^{A}$ falls with migrations, the proportion of entrepreneurs among $\theta_{2^{-}}$ individuals rises even if A remains a many-talent country. Similarly, when country B remains a few-talent country with migrations, the proportion of entrepreneurs among $\theta_{1}$-individuals

must fall with respect to the initial equilibrium since $\lambda_{1}^{B}=\frac{1}{2}\left[1-\frac{\varphi_{2}^{B}}{\varphi_{1}^{B}}\left(\frac{\theta_{2}}{\theta_{1}}\right)^{2}\right]$ and $\frac{\varphi_{2}^{B}}{\varphi_{1}^{B}}$ always increase in B.

Hence, given the initial no-migration equilibrium in A and B, migrations always involve both workers and entrepreneurs, and they make both countries more similar but never identical. In addition, an equilibrium with migrations requires that at least one country falls in the intermediate case and that both do so when migrations are two ways. In all these cases, industry structure in both countries is affected not only by migrations but also by non-migrants' changes in activities. In the next Section, we consider the implications of these changes for the choice of migration policies.

\section{Welfare, Voting and Migration Policies}

To understand some of the policy implications of migrations, we first consider average welfare per capita. For country $i$, the welfare index is measured by total earnings, that is profit and wage. The proportion of $\theta_{2}$-individuals in the economy is $z_{2}^{i}=\varphi_{2}^{i} / h^{i}$, where $h^{i}$ is total population. Average welfare per capita is then,

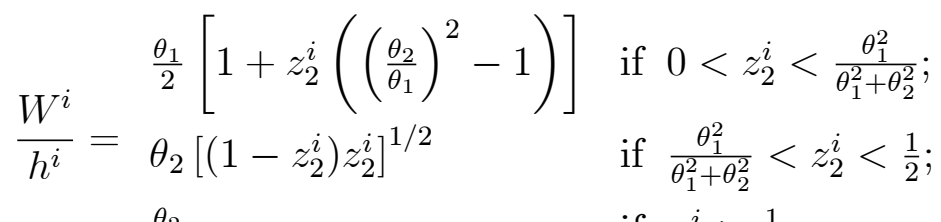

$$
\begin{aligned}
& \frac{\theta_{2}}{2} \quad \text { if } z_{2}^{i}>\frac{1}{2} \text {, }
\end{aligned}
$$

\footnotetext{
${ }^{8}$ They are inconsistent with conditions (5) to (8). For instance, there is no migration when A (B) has still many (few) $\theta_{2}$-individuals. Similarly, migrations cannot make one or both countries become the other country's initial type.
} 
for the few-talent, the intermediate and the many-talent case. It is easy to check that average welfare per capita increases with $z_{2}^{i}$ up to the many-talent case where it is constant. This is because total welfare is a positive convex combination of earnings. In the few-talent case, most individuals have low earnings. In the many-talent case, all the firms are run by the most able entrepreneurs and all the workers earn as much as the entrepreneurs and more than in the few-talent case. ${ }^{9}$ Since half the population is entrepreneurs, this case is characterized by many small firms. Clearly, if country $i$ could select $z_{2}^{i}$, it would always choose to be a many-talent country and despite increasing returns to talent, 'small is beautiful'.

It is easy to extend the welfare analysis when migrations are allowed. With migrations, the proportion of $\theta_{2}$-individuals in the population changes in both countries such that $z_{2}^{A}$ always falls and $z_{2}^{B}$ always rises since $z_{2}^{A}=\left(\varphi_{2}^{A}-y\right) /\left(h^{A}+x-y\right)$ and $z_{2}^{B}=\left(\varphi_{2}^{B}+y\right) /\left(h^{B}+y-x\right)$. The effect of migrations on average welfare per capita is immediate. Remembering that before migrations, B is a few-talent country, its average welfare per capita always increases with migrations. In A, the average welfare per capita decreases except when A remains a many talent country. Although it is a standard result in the literature that the country attracting highly talented individuals (here $\theta_{2}$-individuals) gains while the other one loses, it is interesting to note that country A may not suffer from losing $\theta_{2}$-individuals. This arises because some non-migrating $\theta_{2}$-individuals switch activities and maintain constant the proportion of entrepreneurs in A's population. Similarly, country B gains whether it attracts $\theta_{2}$-individuals or whether it loses $\theta_{1}$-individuals. This arises because migrations induce some individuals in B also to switch activities in response to these migration patterns. However, average welfare per capita does not take into account heterogeneity among individuals. Accordingly, we now consider the case where migration decisions are based on majority voting and thus are determined by self interest. ${ }^{10}$

Recall that, when both countries belong to the intermediate case in the migration equilib-

\footnotetext{
${ }^{9}$ Hence, there is also an equal distribution of earnings. However, $\theta_{2}$-entrepreneurs have higher earnings in the few-talent and in the intermediate case.

${ }^{10}$ See Benhabib (1996), and Bilal, Grether and de Melo (2003) on median voter decisions with migrations issues.
} 
rium, earnings change such that $G_{0}^{A}\left(\theta_{1}\right)>G^{A}\left(\theta_{1}\right), G_{0}^{A}\left(\theta_{2}\right)<G^{A}\left(\theta_{2}\right), G_{0}^{B}\left(\theta_{1}\right)<G^{B}\left(\theta_{1}\right)$ and $G_{0}^{B}\left(\theta_{2}\right)>G^{B}\left(\theta_{2}\right)$. Hence, in A, $\theta_{2}$-individuals prefer migration to no migration and, since it is the many-talent country $\left(\alpha_{0}^{A}=\varphi_{2}^{A} / \varphi_{1}^{A}>1\right)$, their choice reflects the majority decision. Similarly, in B, $\theta_{1}$-individuals prefer migration to no migration and, since $\alpha_{0}^{B}=\varphi_{2}^{B} / \varphi_{1}^{B}<1$, their choice also reflects the majority vote. Whether migrations are one way or two ways, the above earnings inequalities do not change and therefore, both countries always choose to allow migrations when this decision is based on majority voting. This conclusion also holds when one country remains in its inital range with migrations. ${ }^{11}$ This means that both countries support migration policies be they about immigrants, emigrants or both. This strong result arises because activity choices are endogenous and individual's earnings are linked whether they are workers, entrepreneurs, $\theta_{1}$-type or $\theta_{2}$-type individuals.

\section{Conclusions}

The paper has developed a simple two-country-one sector model where individuals are differentiated according to two types of talent. The countries are different in talent endowment and all individuals choose to be workers or entrepreneurs. Allowing migrations generates incentives for the relatively abundant type of individuals to migrate to the other country. There are both workers and entrepreneurs among migrants and, depending on the parameters of the model, there may be one-way or two-way migrations. Because the choice of activity is endogenous, some individuals switch activities when crossing the border and migrations induce some non-migrants to switch activities. As a result industry structure is sensitive to migrations of talented individuals. Finally, the endogenous choice of activities and the interdependance among individual's earnings imply that if a country allows migrations, it does not matter whether the migration policy is about immigrants, emigrants or both.

The model is admittedly simple but it captures some important sylized facts associated

\footnotetext{
${ }^{11}$ Since the other country necessarily falls in the intermediate case, the individuals benefiting from migrations win the decision. Both countries choose to allow migrations but in one, individuals are indifferent between migration and no migration.
} 
with current patterns of migrations and in particular with brain circulation. It is also sufficiently simple to be used to address more complex issues associated with contemporary migration questions. For instance, the model could be expanded to investigate the links between trade and migration flows by linking individuals' types to differentiated products (Manasse and Turrini, 2001; Yeaple, 2003). One could also increase the number of destination countries to understand better why some countries, like the US, seem more successful at attractings talented individuals than others. Finally, talent could be endogenized with the introduction of human capital formation. These are only some of the issues that need to be analyzed to understand the positive and normative aspects of brain circulation, a phenomenon the importance of which is likely to keep growing.

\section{Appendix:}

\subsection{Proof of Proposition 2:}

i) $x>0 ; y=0$ : Since A and B fall in the intermediate case, $\left(\theta_{1} / \theta_{2}\right)^{2}<\alpha^{A}=\varphi_{2}^{A} /\left(\varphi_{1}^{A}+x\right)<$ $1<\alpha_{0}^{A}$ and $0<\alpha_{0}^{B}<\left(\theta_{1} / \theta_{2}\right)^{2}<\alpha^{B}=\varphi_{2}^{B} /\left(\varphi_{1}^{B}-x\right)<1$. In equilibrium, $x$ is determined by (7), which can be written as $\sqrt{\alpha^{A}}-\sqrt{\alpha^{B}}=2 c_{1} / \theta_{2}$. Hence, $\alpha^{A} \geq \alpha^{B}$ when $c_{1} \geq 0$. This case also requires $G_{0}^{A}\left(\theta_{1}\right)-G_{0}^{B}\left(\theta_{1}\right)>c_{1} ; G_{0}^{B}\left(\theta_{2}\right)-G_{0}^{A}\left(\theta_{2}\right) \leq c_{2}$ and $G^{B}\left(\theta_{2}\right)-G^{A}\left(\theta_{2}\right) \leq c_{2}$. It is easy to check that $G^{B}\left(\theta_{2}\right)-G^{A}\left(\theta_{2}\right)<G_{0}^{B}\left(\theta_{2}\right)-G_{0}^{A}\left(\theta_{2}\right) \leq c_{2}$ so that the relevant parameters are determined only by $G_{0}^{B}\left(\theta_{2}\right)-G_{0}^{A}\left(\theta_{2}\right)=\left(\theta_{2}-\theta_{1}\right)\left(\theta_{2} / 2 \theta_{1}\right) \leq c_{2}$ and $G_{0}^{A}\left(\theta_{1}\right)-G_{0}^{B}\left(\theta_{1}\right)=$ $\left(\theta_{2}-\theta_{1}\right) / 2>c_{1}$. It follows that $c_{2}\left(c_{1}\right)$ must be relatively high (low). Since $G_{0}^{A}\left(\theta_{1}\right) G_{0}^{A}\left(\theta_{2}\right)=$ $\left[\theta_{2} / 2\right]^{2}$ and $G_{0}^{B}\left(\theta_{1}\right) G_{0}^{A}\left(\theta_{1}\right)=\theta_{1} \theta_{2} / 4, G_{0}^{B}\left(\theta_{2}\right)-G_{0}^{A}\left(\theta_{2}\right)=\left[\theta_{2} / 2\right]^{2}\left[1 / G_{0}^{B}\left(\theta_{1}\right)-1 / G_{0}^{A}\left(\theta_{1}\right)\right]=$ $\left[\theta_{2} / 2\right]^{2}\left[1 / G_{0}^{B}\left(\theta_{1}\right) G_{0}^{A}\left(\theta_{1}\right)\right]\left[G_{0}^{A}\left(\theta_{1}\right)-G_{0}^{B}\left(\theta_{1}\right)\right]=\left(\theta_{2} / \theta_{1}\right)\left[G_{0}^{A}\left(\theta_{1}\right)-G_{0}^{B}\left(\theta_{1}\right)\right]$. Hence, $G_{0}^{A}\left(\theta_{1}\right)-$ $G_{0}^{B}\left(\theta_{1}\right)>c_{1}$ implies $c_{2} \geq G_{0}^{B}\left(\theta_{2}\right)-G_{0}^{A}\left(\theta_{2}\right)>c_{1}\left(\theta_{2} / \theta_{1}\right)$ and thus $c_{2}>c_{1} \geq 0$.

ii) $x=0 ; y>0$ : Since $\mathrm{A}$ and $\mathrm{B}$ fall in the intermediate case, $\left(\theta_{1} / \theta_{2}\right)^{2}<\alpha^{A}=\left(\varphi_{2}^{A}-\right.$ $y) / \varphi_{1}^{A}<1<\alpha_{0}^{A}$ and $0<\alpha_{0}^{B}<\left(\theta_{1} / \theta_{2}\right)^{2}<\alpha^{B}=\left(\varphi_{2}^{B}+y\right) / \varphi_{1}^{B}<1$. In equilibrium, $y$ is determined by (8), which can be written as $1 / \sqrt{\alpha^{B}}-1 / \sqrt{\alpha^{A}}=2 c_{2} / \theta_{2}$. Hence, $\alpha^{A} \geq \alpha^{B}$ when $c_{2} \geq 0$. This case also requires $G_{0}^{A}\left(\theta_{1}\right)-G_{0}^{B}\left(\theta_{1}\right) \leq c_{1} ; G_{0}^{B}\left(\theta_{2}\right)-G_{0}^{A}\left(\theta_{2}\right)>c_{2} ; G^{A}\left(\theta_{1}\right)-$ 
$G^{B}\left(\theta_{1}\right) \leq c_{1}$ and the relevant parameters are determined only by $G_{0}^{A}\left(\theta_{1}\right)-G_{0}^{B}\left(\theta_{1}\right) \leq c_{1}$ and $G_{0}^{B}\left(\theta_{2}\right)-G_{0}^{A}\left(\theta_{2}\right)>c_{2}$. Hence, $c_{1}\left(c_{2}\right)$ must be relatively low (high) but positive. As above, $G_{0}^{B}\left(\theta_{2}\right)-G_{0}^{A}\left(\theta_{2}\right)=\left(\theta_{2} / \theta_{1}\right)\left[G_{0}^{A}\left(\theta_{1}\right)-G_{0}^{B}\left(\theta_{1}\right)\right]$ so that $c_{2}<G_{0}^{B}\left(\theta_{2}\right)-G_{0}^{A}\left(\theta_{2}\right) \leq\left(\theta_{2} / \theta_{1}\right) c_{1}$ which implies $c_{2}<\left(\theta_{2} / \theta_{1}\right) c_{1}$. Thus, $c_{1}=c_{2}$ is consistent with these inequalities as long as they are positive.

\subsection{Proof of Proposition 3:}

Suppose $\mathrm{A}$ has still many $\theta_{2}$-individuals and $\mathrm{B}$ falls in the intermediate case with migrations. This case implies $0<\alpha_{0}^{B}<\left(\theta_{1} / \theta_{2}\right)^{2}<\alpha^{B}=\left(\varphi_{2}^{B}+y\right) /\left(\varphi_{1}^{B}-x\right)<1<\alpha^{A}=\left(\varphi_{2}^{A}-\right.$ $y) /\left(\varphi_{1}^{A}+x\right)<\alpha_{0}^{A}$ with $G_{0}^{A}\left(\theta_{1}\right)=G^{A}\left(\theta_{1}\right)=G_{0}^{A}\left(\theta_{2}\right)=G^{A}\left(\theta_{2}\right)=\theta_{2} / 2, G_{0}^{B}\left(\theta_{1}\right)=\theta_{1} / 2$, $G_{0}^{B}\left(\theta_{2}\right)=\left(\theta_{2} / 2\right)\left(\theta_{2} / \theta_{1}\right), G^{B}\left(\theta_{1}\right)=\left(\theta_{2} / 2\right) \sqrt{\alpha^{B}}$ and $G^{B}\left(\theta_{2}\right)=\left(\theta_{2} / 2\right)\left(1 / \sqrt{\alpha^{B}}\right)$. When $x>0$ and $y>0,(7)$ and (8) can be written as $1-\sqrt{\alpha^{B}}=n_{1}$ and $\sqrt{\alpha^{B}}=c_{1} / c_{2}$, which implies that $c_{2}=\theta_{2} c_{1} /\left(\theta_{2}-2 c_{1}\right)$. This case almost never arises since this is the only possible parameter combination. When $x>0$ and $y=0,1-\sqrt{\alpha^{B}}=n_{1}$ determines $x$. Among the three inequalities that must also hold, only $G_{0}^{A}\left(\theta_{1}\right)-G_{0}^{B}\left(\theta_{1}\right)>c_{1}$ and $G_{0}^{B}\left(\theta_{2}\right)-G_{0}^{A}\left(\theta_{2}\right) \leq c_{2}$ matter. They are $c_{2}>\left(\theta_{2} / 2 \theta_{1}\right)\left(\theta_{2}-\theta_{1}\right)$ and $(1 / 2)\left(\theta_{2}-\theta_{1}\right)>c_{1}$ implying that $c_{2}>c_{1}$. When $x=0$ and $y>0,1 / \sqrt{\alpha^{B}}-1=n_{2}$ determines $y$ uniquely. Among the three inequalities that must hold in equilibrium, only $G_{0}^{A}\left(\theta_{1}\right)-G_{0}^{B}\left(\theta_{1}\right) \leq c_{1}$ and $G_{0}^{B}\left(\theta_{2}\right)-G_{0}^{A}\left(\theta_{2}\right)>c_{2}$ matter so that $c_{1}=c_{2}$ is consistent with the equilibrium. The proof for the case in which A falls in the intermediate case and $\mathrm{B}$ has still few $\theta_{2}$-individuals is similar.

\section{References}

[1] Benhabib, J. (1996), 'On the Political Economy of Immigration', European Economic Review, 40, 1737-43.

[2] Bhagwati, J. and J. Wilson (1989), 'Income Taxation and International Mobility', Cambridge, MA: MIT Press. 
[3] Bilal, S.; J.-M. Grether and J. de Melo (2003), 'Attitudes Towards Immigration: A Trade-Theoretic Approach', Review of International Economics

[4] Gera, S; S. Laryea and T. Songsakul (2004), 'International Mobility of Skilled Labour: Beyond 'Brain Drain”, mimeo, Industry Canada

[5] Grossman, G. (1984), 'International Trade, Foreign Investment, and the Formation of the Entrepreneurial Class', American Economic Review,74, 4, 605-14.

[6] Harris, R. (2004), 'Labour Mobility and the Global Competition for Skills: Dilemmas and Options', mimeo, Simon Fraser University.

[7] Johnson, J. and M. Regets (1998), 'International Mobility of Scientists and Engineers to the United States: Brain Drain or Brain Circulation?', Issue Brief, National Science Foundation, NSF 98-316, June.

[8] Lucas, R.E. (1978), 'On the Size Distribution of Business Firms', Rand Journal of Economics, IX, 508-23.

[9] Manasse, P. and A. Turrini (2001), 'Trade, Wages and 'Superstars", Journal of International Economics, 54, 97-117.

[10] Murphy, K.M.; Shleifer, A. and R.W. Vishny (1991), 'The Allocation of Talent: Implications for Growth', Quaterly Journal of Economics, 503-30.

[11] OECD (2002), OECD Science, Technology and Industry Outlook, Paris.

[12] OECD (2001), 'International Mobility of Highly Skilled Workers: from Statistical Analysis to the Formulation of Policies', COM/DSTI/DEELSA(2001)37, May 30.

[13] Rauch, J.E. (1991), 'Reconciling the Pattern of Trade with the Pattern of Migration', American Economic Review 81, 4, 775-96.

[14] Yeaple, S. (2003), 'Firm Heterogeneity, International Trade and Wages', mimeo, University of Pennsylvania. 
[15] Zucker, L and M. Darby (1999), 'Star-scientist linkages to firms in APEC and European countries: indicators of regional institutional differences affecting competitive advantage', International Journal of Biotechnology, 1(1), 119-31.

[16] Zucker, L. and M. Darby (1995), 'Virtuous Circles of Productivity: Star Bioscientists and the Institutional Transformation of Industry', NBER WP 5342, November. 


\title{
CESifo Working Paper Series
}

\author{
(for full list see www.cesifo-group.de)
}

1417 Samuel Mühlemann, Jürg Schweri, Rainer Winkelmann and Stefan C. Wolter, A Structural Model of Demand for Apprentices. February 2005

1418 Giorgio Brunello and Lorenzo Rocco, Educational Standards in Private and Public Schools, February 2005

1419 Alex Bryson, Lorenzo Cappellari and Claudio Lucifora, Why so Unhappy? The Effects of Unionisation on Job Satisfaction, March 2005

1420 Annalisa Luporini, Relative Performance Evaluation in a Multi-Plant Firm, March 2005

1421 Giorgio Bellettini and Carlotta Berti Ceroni, When the Union Hurts the Workers: A Positive Analysis of Immigration Policy, March 2005

1422 Pieter Gautier, Michael Svarer and Coen Teulings, Marriage and the City, March 2005

1423 Ingrid Ott and Stephen J. Turnovsky, Excludable and Non-Excludable Public Inputs: Consequences for Economic Growth, March 2005

1424 Frederick van der Ploeg, Back to Keynes?, March 2005

1425 Stephane Dees, Filippo di Mauro, M. Hashem Pesaran and L. Vanessa Smith, Exploring the International Linkages of the Euro Area: a Global VAR Analysis, March 2005

1426 Hans Pitlik, Friedrich Schneider and Harald Strotmann, Legislative Malapportionment and the Politicization of Germany’s Intergovernmental Transfer System, March 2005

1427 Konstantinos Angelopoulos and Apostolis Philippopoulos, The Role of Government in Anti-Social Redistributive Activities, March 2005

1428 Ansgar Belke and Daniel Gros, Asymmetries in the Trans-Atlantic Monetary Policy Relationship: Does the ECB follow the Fed?, March 2005

1429 Sören Blomquist and Luca Micheletto, Optimal Redistributive Taxation when Government's and Agents’ Preferences Differ, March 2005

1430 Olof Åslund and Peter Fredriksson, Ethnic Enclaves and Welfare Cultures - QuasiExperimental Evidence, March 2005

1431 Paul De Grauwe, Roberto Dieci and Marianna Grimaldi, Fundamental and NonFundamental Equilibria in the Foreign Exchange Market. A Behavioural Finance Framework, March 2005

1432 Peter Egger, Stefan Gruber, Mario Larch and Michael Pfaffermayr, Knowledge-Capital Meets New Economic Geography, March 2005 
1433 George Economides and Apostolis Philippopoulos, Should Green Governments Give Priority to Environmental Policies over Growth-Enhancing Policies?, March 2005

1434 George W. Evans and Seppo Honkapohja, An Interview with Thomas J. Sargent, March 2005

1435 Helge Berger and Volker Nitsch, Zooming Out: The Trade Effect of the Euro in Historical Perspective, March 2005

1436 Marc-Andreas Muendler, Rational Information Choice in Financial Market Equilibrium, March 2005

1437 Martin Kolmar and Volker Meier, Intra-Generational Externalities and InterGenerational Transfers, March 2005

1438 M. Hashem Pesaran and Takashi Yamagata, Testing Slope Homogeneity in Large Panels, March 2005

1439 Gjermund Nese and Odd Rune Straume, Industry Concentration and Strategic Trade Policy in Successive Oligopoly, April 2005

1440 Tomer Blumkin and Efraim Sadka, A Case for Taxing Education, April 2005

1441 John Whalley, Globalization and Values, April 2005

1442 Denise L. Mauzerall, Babar Sultan, Namsoug Kim and David F. Bradford, Charging $\mathrm{NO}_{x}$ Emitters for Health Damages: An Exploratory Analysis, April 2005

1443 Britta Hamburg, Mathias Hoffmann and Joachim Keller, Consumption, Wealth and Business Cycles in Germany, April 2005

1444 Kohei Daido and Hideshi Itoh, The Pygmalion Effect: An Agency Model with Reference Dependent Preferences, April 2005

1445 John Whalley, Rationality, Irrationality and Economic Cognition, April 2005

1446 Henning Bohn, The Sustainability of Fiscal Policy in the United States, April 2005

1447 Torben M. Andersen, Is there a Role for an Active Fiscal Stabilization Policy? April 2005

1448 Hans Gersbach and Hans Haller, Bargaining Power and Equilibrium Consumption, April 2005

1449 Jerome L. Stein, The Transition Economies: A NATREX Evaluation of Research, April 2005

1450 Raymond Riezman, John Whalley and Shunming Zhang, Metrics Capturing the Degree to which Individual Economies are Globalized, April 2005 
1451 Romain Ranciere, Aaron Tornell and Frank Westermann, Systemic Crises and Growth, April 2005

1452 Plutarchos Sakellaris and Focco W. Vijselaar, Capital Quality Improvement and the Sources of Growth in the Euro Area, April 2005

1453 Kevin Milligan and Michael Smart, Regional Grants as Pork Barrel Politics, April 2005

1454 Panu Poutvaara and Andreas Wagener, To Draft or not to Draft? Efficiency, Generational Incidence, and Political Economy of Military Conscription, April 2005

1455 Maurice Kugler and Hillel Rapoport, Skilled Emigration, Business Networks and Foreign Direct Investment, April 2005

1456 Yin-Wong Cheung and Eiji Fujii, Cross-Country Relative Price Volatility: Effects of Market Structure, April 2005

1457 Margarita Katsimi and Thomas Moutos, Inequality and Relative Reliance on Tariffs: Theory and Evidence, April 2005

1458 Monika Bütler, Olivia Huguenin and Federica Teppa, Why Forcing People to Save for Retirement may Backfire, April 2005

1459 Jos Jansen, The Effects of Disclosure Regulation of an Innovative Firm, April 2005

1460 Helge Bennmarker, Kenneth Carling and Bertil Holmlund, Do Benefit Hikes Damage Job Finding? Evidence from Swedish Unemployment Insurance Reforms, May 2005

1461 Steffen Huck, Kai A. Konrad and Wieland Müller, Merger without Cost Advantages, May 2005

1462 Louis Eeckhoudt and Harris Schlesinger, Putting Risk in its Proper Place, May 2005

1463 Hui Huang, John Whalley and Shunming Zhang, Trade Liberalization in a Joint Spatial Inter-Temporal Trade Model, May 2005

1464 Mikael Priks, Optimal Rent Extraction in Pre-Industrial England and France - Default Risk and Monitoring Costs, May 2005

1465 François Ortalo-Magné and Sven Rady, Heterogeneity within Communities: A Stochastic Model with Tenure Choice, May 2005

1466 Jukka Pirttilä and Sanna Tenhunen, Pawns and Queens Revisited: Public Provision of Private Goods when Individuals make Mistakes, May 2005

1467 Ernst Fehr, Susanne Kremhelmer and Klaus M. Schmidt, Fairness and the Optimal Allocation of Ownership Rights, May 2005

1468 Bruno S. Frey, Knight Fever - Towards an Economics of Awards, May 2005 
1469 Torberg Falch and Marte Rønning, The Influence of Student Achievement on Teacher Turnover, May 2005

1470 John Komlos and Peter Salamon, The Poverty of Growth with Interdependent Utility Functions, May 2005

1471 Hui Huang, Yi Wang, Yiming Wang, John Whalley and Shunming Zhang, A Trade Model with an Optimal Exchange Rate Motivated by Current Discussion of a Chinese Renminbi Float, May 2005

1472 Helge Holden, Lars Holden and Steinar Holden, Contract Adjustment under Uncertainty, May 2005

1473 Kai A. Konrad, Silent Interests and All-Pay Auctions, May 2005

1474 Ingo Vogelsang, Electricity Transmission Pricing and Performance-Based Regulation, May 2005

1475 Spiros Bougheas and Raymond Riezman, Trade and the Distribution of Human Capital, June 2005

1476 Vesa Kanniainen, Seppo Kari and Jouko Ylä-Liedenpohja, The Start-Up and Growth Stages in Enterprise Formation: The "New View" of Dividend Taxation Reconsidered, June 2005

1477 M. Hashem Pesaran, L. Vanessa Smith and Ron P. Smith, What if the UK had Joined the Euro in 1999? An Empirical Evaluation Using a Global VAR, June 2005

1478 Chang Woon Nam and Doina Maria Radulescu, Effects of Corporate Tax Reforms on SMEs’ Investment Decisions under the Particular Consideration of Inflation, June 2005

1479 Panos Hatzipanayotou, Sajal Lahiri and Michael S. Michael, Globalization, CrossBorder Pollution and Welfare, June 2005

1480 John Whalley, Pitfalls in the Use of Ad valorem Equivalent Representations of the Trade Impacts of Domestic Policies, June 2005

1481 Edward B. Barbier and Michael Rauscher, Trade and Development in a Labor Surplus Economy, June 2005

1482 Harrie A. A. Verbon and Cees A. Withagen, Tradable Emission Permits in a Federal System, June 2005

1483 Hendrik Hakenes and Andreas Irmen, On the Long-Run Evolution of Technological Knowledge, June 2005

1484 Nicolas Schmitt and Antoine Soubeyran, A Simple Model of Brain Circulation, June 2005 